\title{
Regulation of training systems for adults in educational technology
}

\author{
Brigitte Denis and Sylvie-Anne Piette \\ Service de Technologie de l'Education University of Liège (Belgium)
}

\begin{abstract}
This paper reports the characteristics of a post graduate diploma on educational technologies based on a combination of face-to-face and distance activities and assesses its quality. We first define the bases of the training program and present several tools (logbook, portfolio and questionnaires) which have been used to evaluate and regulate both training and the individual learning process. Our observations indicate an increase and better regulation of the quality of the educational and learning processes. On the basis of the results we achieved, we propose that our original design could be extended to similar adult training programs. The way this innovative system is integrated in the universities shows an evolution due to its success that implies a certain kind of return on investment due to the demand of such kinds of device.
\end{abstract}

Keywords blended learning, quality, evaluation, portfolio, educational technology, postagraduate.

\section{INTRODUCTION}

Three years ago, two Belgian universities (ULG \& FUNDP) put their resources together to start a new postgraduate program in educational and training technology combining face-to-face and distance activities. This program ('Diplôme d'Etudes Spécialisées en Technologie de l'Education et de la Formation' see http://www.ulg.ac.be/ste/destef/, DES-TEF) targets graduates with professional experience in training. They are from various backgrounds (companies, primary and secondary schools, universities and public organisations). Depending on their initial profiles and personal projects, different profiles of competencies can be developed as, for example, pedagogical designer, training systems manager, on line tutor, or

The original version of this chapter was revised: The copyright line was incorrect. This has been corrected. The Erratum to this chapter is available at DOI: 10.1007/978-0-387-35700-3_33 
multimedia product designer. Everyone of these uses Information and Communication Technologies (ICT) as well as active learning methods based on the teaching and learning paradigms defined by Denis \& Leclercq (1994). All learners design their own personal project which leads them to choose specific courses to realise it.

We describe some criteria for a quality control of the training and learning system of the DES-TEF and some regulation tools we used to improve it. Quantitative and qualitative evaluations have been made, mainly at a micro level by collecting data from learners and teachers. Our analysis focused on the regulation of the individual learning process and of the training system. Some effects at the institutional level are also considered. Our observations suggest strongly that this methodology is efficient in a hybrid education system, combining distance and presence learning in a context of professional development. Therefore, we propose to apply this approach to similar systems.

\section{EVALUATION CRITERIA FOR ASSESSING AND IMPROVING THE TRAINING SYSTEM QUALITY}

Quality deals with all the properties and characteristics of a product, a process or a service that permit the satisfaction of explicit or implicit needs. The concept of quality control is based on the idea that every product, production process or service should be checked and improved if necessary. As education is a part of the economy of services (Charlier, Bonamy \& Saunders 2002), it should be looked at whether or not it fills the explicit and/or implicit needs of its actors and of the institutions.

In our context, we are interested in testing how we can regulate and optimise the training and learning system, and process when the main actors of this process are implicated in its own regulation. Indeed, the participants of the DES-TEF do not only consume the training service, they also produce a part of it. This co-production phenomena by the 'client' is what the economists would call servuction (e.g. self banking, self learning).

Now let's consider which characteristics we took into account in our quality assurance concerning the training system of the DES-TEF. We could have referred to many aspects of the system (see the model of the 'diamond' from Leclercq et al. 2000) or could have assessed the quality at each stage of the production or each use of the service, but we decided to focus on the following criteria: (1) the answer to the client's demand, (2) a learner based approach, (3) a pedagogical contract, (4) the follow up of the learner, (5) the actors' training and competencies, (6) the adequacy and added value of the 
educational and technological resources, (7) a co-evaluation and a regulation process and (8) the return on the investment.

\subsection{The answer to the client's demand}

These quality criteria mainly refer to the matching of the learner needs and the training proposal.

A previous survey indicated that there was a deficiency in the domain of training in the use of ICTE (Information and Communication Technologies for Education) at local and national level in Belgium. Therefore, two universities combined their efforts to develop such a common training curriculum.

The system tries to match the learners' needs by providing a flexible curriculum with some activities at a distance and by enhancing their participation in defining their training program (Kremers \& Piette, 1999). Five common modules introduce basic theories and principles concerning the following areas: training and learning, training systems, multimedia design and production, evaluation and management of ICTE resources. Then, the learners choose specialised courses in these modules depending on what they need for the materialization of their project. To maximise the personal investment of the participants, we emphasise the link between the professional activities and the educational technologies.

Adjustments to new demands are also possible as the teacher's team tries to regulate the curriculum as the training proceeds (see later).

\subsection{A learner-based approach}

E-learning and learning systems adapted to adults share common features: they both focus on the learners and their autonomy. Indeed, they are responsible for defining their own learning needs, for the conception of their project, for the way to realise it and for the evaluation of the learning effects (Leclercq \& Denis, 1996).

Knowles (1990) pointed out two elements for adults' training evaluation. On the one hand, there is a necessity for self-diagnosis and on the other hand, a need for a shared evaluation of apprenticeship, program and course design between the learner and the trainer. Self-diagnosis could be defined by the identification and expression of a lack of competencies or through a personal project of apprenticeship - as it is the case in the DES-TEF program. Therefore, the personal implication of the students in the definition of their own learning project should improve their self-evaluation and the integration of the training (Kaufman, 1999). About apprenticeship evaluation, Meirieu (2000, p. 96) proposes to formulate indicators of results 
of the mental process, instead of objectives lists for assessment. To assess these indicators in the DES-TEF, we developed adapted tools such as logbooks, forums and regulation sessions.

\subsection{A pedagogical contract}

The pedagogical contract, described by Carré and Pearn (1992, p.50), as a basis for self-learning is also certainly a quality criterion in all kinds of training, but it is particularly the case in adult training combining distance and in attendance strategies.

The four goals we want to achieve by using this contract are: to formalise the individual project, to clarify the negotiation between the learner and other partners, to structure the self-learning process and to facilitate the evaluation. These four categories can then be tagged as objectives (described in observable facts as much as possible), resources (both material and human), logistics (place, budget, calendar) and evaluation (methods, criteria). This tagging is necessary to clarify the functions of the tools, which will be used during the training and to define precisely everyone's role.

In the case of the DES-TEF, this stage was done through the definition and the communication of its basic principles.

\section{$2.4 \quad$ The learners' follow-up}

Adults learning, self-learning and e-learning do not imply that the learner is alone (Denis, 1997). At each stage of their learning process, the learners can get help and advice from the educational staff, as, for example, to precise their needs, to reflect on their apprenticeship, etc. In the DES-TEF, we attach a resource person to each learner, a supervisor for the follow up of his/her project. Feedback on the activities are given by the instructors. We strongly encourage interaction and collaboration between the learners to solve problems or to realise prescribed activities.

\subsection{The actors training and competencies}

The development of an e-learning system requires the participation of many actors and the description of new jobs. These actors need specific competencies (le Préau, 2001) to produce service. Co-ordination is then necessary to collect and communicate useful information for regulation. In the DES-TEF, many actors are experts in technologies of education. A single person has often several roles: pedagogical designer, technical producer, tutor, teacher, evaluator. The system is quite dynamic, meaning 
that since its conception, it has evolved. Some people have specialised in a particular function. For instance, some tutors have been assigned to different courses. To achieve this, we organised training sessions for the tutors in order to clarify their roles in the program and to try to match them with the instructors' goals.

As we said previously, the main aim of the training program is to increase the competencies of the learners in different topics, related to ICTE. A portfolio is used to monitor the evolution of the work of the learners. As the program implies the use of technical tools, the learners need to be familiar with them. Therefore we defined some basic technical skills we estimated were necessary to let them use efficiently the pedagogical support and communication tools. We ask them to self-evaluate their competencies and decide if they need extra training.

\subsection{The adequacy and added value of the educational and technological resources}

To be efficient, we had to develop specific pedagogical resources and activities to match the objectives of the training program. Some questions emerge immediately. If the resources and activities are available on line, what is their real added value? Are they only electronic books or do they offer an interactive way of learning, that will achieve a better understanding of the topic for the learner? Do the instructions about the activities enhance links with the concepts or tools developed in the courses? Are these activities adapted to reach the educational goals? Are the contents and the theoretical framework up to date? Do the user interface and the electronic supports respect basic ergonomic principles such as controllability, homogeneity, usability?

It goes without saying that the choice of the technological tools is also important. If we consider a distance training system, what is the quality of its platform (ORAVEP, 2000 ; Le Préau 1999 \& 2000 ; Gram et al, 1998) ? Does it make it possible to develop all the requested activities? Are the tools used for certain activities such as the collaborative learning adequate not only for its realisation but also for its timing (cf. Lewis, 1996)?

\subsection{A co-evaluation and regulation process}

Each training system, whatever its educational environment, needs to be regulated at one time. Different variables could be used for this purpose: analysis of the needs (e.g. adaptation of the curriculum to new needs), learning objectives, methods, and evaluation criteria. In higher education (university level), commissions of experts and teams of instructors evaluate 
the training system in order to ameliorate its quality. An assessment of the teaching itself (but not of the instructors) has also been developed (see http://www.smart.ulg.ac.be/index.php3).

Once again, the identification of the actors who contribute to the regulation is primordial. In the DES-TEF program, we established a specific structure, called the management committee, that deals with the problems of the admission of the participants, the attribution of a resource person to each participant, the modifications of the curriculum, the adaptation of the diary, the regulation of the courses and specific problems of some students. This committee is composed of training staff members who use information coming from different sources: learners' portfolios and logbooks, questionnaires, interviews and focus groups. The committee meets four times a year. As the information source comes from the learners themselves, they are also actors within the regulation process.

\subsection{The return on investment}

It is not our purpose to analyse the costs of the design and the implementation of such a training system in this paper. We will consider only the number of people who are awarded the diploma at the end of the program and the way this innovative system has been implemented.

\section{EVALUATION TOOLS}

From its start, a constant evaluation and regulation process of the DESTEF has been performed. We focus now on the nature of the tools and the support we used in the evaluation of the individual learning process and of the training strategy.

\subsection{Logbooks}

To keep track of their own progress (by mainly self-assessment) during the learning, the learners keep notes in a logbook. The logbook contains information on the learning experiences of the learner. Each learner can express his/her personal experience of learning at cognitive and socioaffective levels. They write what has been learned in which context and tell their positive and negative experiences of learning. Our hypothesis is that the use of the logbook could help them to build a positive self-image because it shows the evolution of the learning (from the starting point to the achievement) and the possibilities to transfer this apprenticeship. 
We conceive it as a tool that offers the possibility of developing a socioconstructivist pedagogy (Bruner, Piaget) and that, in addition, contributes to the data collection to be evaluated if some of our quality criteria are encountered. The analysis of the use of the logbook helps us to answer some of our questions: Is it really 'a learner-based approach'? What about the 'pedagogical contract', the 'learner's follow up' and the 'answer to the client's demand' with the help of the resource person? Does it provide huge information permitting the 'co-regulation' of the training system and of the individual learning process?

A first version of the logbook has been adapted after the first year to address different remarks. First, the questions were more precise and dealt more obviously with the individual, relational and environmental variables as described by Charlier (1998). The idea being that the analysis of these variables during the learning process should allow a better regulation of the learning process (e.g. choices, expectations, learning methods, more or less implication in a type of activity) as well as the way of learning. We planned this regulation as dialogue with a resource-person dedicated to each individual learner. Another role of this resource person is to help him/her to choose the specific courses that will best fit the needs expressed by the learner and observed by previous contacts. The best person to play this role will be somebody who has a deep knowledge and a good representation of the learning system. The dialogue with his/her resource person relies on the logbook where the participant regularly writes about his/her analysis.

Piette, (2001), used logbooks as a tool of regulation and meta evaluation and showed that the logbook can be a good indicator of the evolution of the mental process for both the learner and the instructor.

\subsection{Portfolio}

All the learner's productions linked to the activities of the different courses are gathered in a portfolio, which is also a tool for self-evaluation (St. James, 1998). The learners drag their work into a folio on a website, so that the instructors can access the student production easily, read the documents and react. This collection of data is important for the trainees themselves to keep track of their work but also, it allows a self-analysis through their successive productions. They can also use this folder as a storage item for all documents they consider relevant for completion of their project (tools, references, etc.).

Why is the portfolio a way of testing our quality criteria? Because it illustrates how far the 'pedagogical contract' is respected as it contains the products of the learners' activities for which the evaluation steps have been described. By looking back to their own production, the learners can then 
measure the 'evolution of their competencies' and contribute efficiently to develop the requested 'based learners' approach'.

The instructors evaluate the learners' productions as a 'follow up' to their work. At this step, the portfolio provides an opportunity to get some feedback on the learning device itself. Feedback is given to the trainees individually or through a collective debriefing. If too many students failed to achieve good quality work, one can wonder if the learning system does not present some weaknesses in the way the instructions have been provided or in the nature of the chosen activity. In this case, a complete review would have to be done to solve the problem.

\subsection{Questionnaires}

During the first year, the students systematically answered a questionnaire at the end of each compulsory course. This data collection had multiple goals. For instance, it allowed us to collect information on the added value of the distance training (providing web supports with hyperlinks in the courses notes, their effective use, activities to be made at a distance) and also on the different teaching and learning methods proposed (e.g. case studies, collaborative learning (Henri \& Lundgren-Cayrol, 2002), PARM method, LQRT method (Leclercq, 1998)), on the use of ICT tools, etc.).

We can point out from these questionnaires that the indicators of evolution have helped us to reinforce the 'learner' based approach.

\section{SOME EFFECTS AT THE INSTITUTIONAL LEVEL}

Even though, distance learning projects had already been experienced in both universities (Charlier et Peraya, 2002), the DES-TEF is the first full post graduate diploma, combining distance and face-to-face learning in these institutions. This innovative program is intended to adapt training practices and to include ICT tools to design innovative activities linked to educational technologies. It has to be noted that no additional staff have been provided by the institutions to start the program. All the instructors were volunteers and had to add this charge to their already existing load.

After two years, an assistant has been appointed to improve the management of the distance learning platform and the tutorial for some activities. A tutors online training was designed (Denis, 2003) and applied in this context. We have then moved a step forward in the acknowledgement of our original concept as we received help from the authorities of the university. This is one fundamental step to an official recognition of the 
training program (we were before just authorised to organise the program). This is probably a consequence of a return on the investment made. Indeed, we are very close to the critical average number of certificated people per three year period, a pre-requisite for state subsidy.

\section{CONCLUSION}

The DES-TEF has been created to answer a real need in the development of competencies in the design and the use of ICTE in Belgium. So far, it has proved to be a great success. Furthermore, this training system is innovative and original as it emerges from the combination of innovative pedagogical methods and technological tools. In this new system, using qualitative and quantitative methods and tools regularly regulates the teaching and learning processes. Logbooks, portfolios, questionnaires and regulation meetings between students and instructors provide a huge amount of information and allow both parties to discuss several aspects of the training device. This has a dynamic impact on the device as together they think and conceive the future improvement for the following years. Many components of the system are adapted to fulfil the best learning needs of people interested in the use of ICTE and improve the quality of the system.

To assess the value of our program, we performed quality control and regulation at several levels. At an individual level, learners reflect and 'take distance' about their own learning strategies, their personal development and about the proposed courses in order to regulate them. Instructors meet regularly to develop strategies for a better adaptation of the system. The role of the resource persons, as we designed it is to support the learners with help, information and feedback to the students about their understanding . The system implies that all actors share their experiences to develop a community of practice (Henri \& Pudelko, 2002).

\section{REFERENCES}

Bonamy, J., Charlier, B. Saunders, M. (2002) Issues in the organisational and change context for innovations using ICTs in Higher Education, WCCC 2002, Montréal.

Carré P. \& Pearn M. (1992) L'auto-formation dans l'entreprise, Paris. Entente.

Charlier, B. (1998). Apprendre et changer d'enseignement : expériences d'enseignants. Bruxelles. De Boeck.

Charlier, B. Bonamy, J. \& Saunders, M. (2002). Apprivoiser l'innovation. In Charlier, B \& Peraya, D. (2002). Nouveaux dispositifs de formation pour l'enseignement supérieur. Allier technologies et innovations. Bruxelles, De Boeck.

Charlier , B. et Perraya, D. (eds) (2002). Nouveaux dispositifs de formation pour l'enseignement supérieur. Allier technologies et innovations. Bruxelles, De Boeck. 
Denis, B. (1997). Self-learning activities in the French Community of Belgium, in Straka, G., A European View of self-directed learning, Bremen, University Press, 1997, 39-58.

Denis, B. (2003). Comment former les tuteurs intervenant dans des dispositifs d'apprentissage à distance ?, Distances et savoirs, Vol. 1- $\mathrm{n}^{\circ} 1 / 2003$.

Denis, B. \& Leclercq, D. (1994). The fundamental IDs and their associated problems. in J. Lowyck and J. Elen, Modelling I.D. Research, Proceedings of the first workshop of the special interest group on instructional design of EARLI, Leuven, June 17-19, 1994, pp.6783.

Gram, T., Mark, T. \& McGreal, R. (1998). A survey of New Media Development and Delivery Software for Internet-Based Learning. Industry Canada. Science Promotion and Academics Affairs Branch.

Henri, F. \& Lundgren-Cayrol, K. (2002). Apprentissage collaboratif à distance. Pour comprendre et concevoir les environnements d'apprentissage virtuels. Québec. Presses de l'université du Québec.

Henri, F. et Pudelko, B. (2002). La recherche sur la communication asynchrone : de l'outil aux communautés, in Daele, A. et Charlier, B. (eds). Les communautés délocalisées d'enseignants. Etude du Programme de Numérisation pour l'Enseignement et la Recherche (PNER). Paris, mars 2002

Kaufman D. (1999). Le Nouveau Paradigme dans l'Enseignement Médical: Comment la théorie peut exercer une influence sur la Pratique, 13ème journée universitaire francophones de pédagogie médicale, Université de Nantes. http://www.cidmef.ubordeaux 2 .fr/wnantes/texte 2 .htm

Kremers C. \& Piette, S.-A. (1999). Etre co-pilote de sa propre formation en entreprise, colloque EARLI, Göteborg, sept.99. http://www.crifa.fapse.ulg.ac.be/flexifor/pgenjeux.htm

Knowles, M. (1990). L'apprenant Adulte, Vers un Nouvel Art de la Formation, Paris. les éd. d'organisation.

Leclercq, D. (1998). Pour une pédagogie universitaire de qualité. Liège : Mardaga.

Leclercq, D. et al. (2000). Dispositifs d'Apprentissage et Modèles Appliqués aux Nouvelles Technologies (DIAMANT). Service de Technologie de l'Education, Université de Liège, document interne.

Leclercq, D. \& Denis, B. (1996). Auto-formation et hypermédias ? Qu'est-ce qu'un bon autoapprenant ? Deuxième colloque européen sur l'auto-formation. Pratiques d'auto-formation et d'aide à l'auto-formation. Université des Sciences et Technologies de Lille USTL (novembre 1995). Les cahiers du CUEEP, 1996, 32-33, 155-161.

Le Préau (1999-2000-2001). Quel modèle qualité pour la e-formation ? «Les normes qualités existantes répondent-elles aux besoins des acteurs de la e-formation?» http://www.preau.ccip.fr/qualite/index.php

Lewis, R. (1996). Working and Learning in Distributed Communities. Universidad Autonoma de Madrid, June 1996 seminar, Computer Supported Learning Environments.

Meirieu P., Savoirs et compétences en éducation, formation et organisation, actes de forum, éd DEMOS, 2000.

ORAVEP (2000). Étude comparative technique et pédagogique des plates-formes pour la formation ouverte et à distance. http://www.educnet.education.fr/superieur/plateforme.htm

Piette, S.-A. (2001). Le carnet de bord comme outil de formalisation personnelle de ses acquis. Mémoire de Diplôme d'Etudes Spécialisées en Technologie de l'Education et de la Formation (DES-TEF). Université de Liège.

St. James, S. (1998) Le portfolio : un levier pour l'amélioration de l'enseignement. Mesure et evaluation en éducation. Vol. 21

Straka, G. (1997). A European View of self-directed learning. Bremen. University Press 